\title{
Analysis of multiple criteria selection and application of APEKS method in haul truck mining transport process
}

\author{
Michat Patyk ${ }^{1, *}$ and Przemystaw Bodziony ${ }^{1}$ \\ ${ }^{1}$ AGH University of Science and Technology, Faculty of Mining and Geoengineering 30 A. Mickiewicz Av., $30-059$ Kraków, \\ Poland
}

\begin{abstract}
Vehicle transport is a dominant type of technological processes in rock mines, and its profitability is strictly dependent on overall cost of exploitation. Rational design of mining transportation system based on haul trucks should result from thorough analysis of technical and economic issues, including both cost of purchase and its further exploitation, having a crucial impact on the cost of minerals extraction. Moreover, haul trucks should be selected with type of payload. In this paper a development of universal family of evaluation criteria as well as application of evaluation method for haul truck and processing system selection process for a specific exploitation conditions in surface mining have been carried out. This methodology presented in the paper is based on the principles of multicriteria optimization using one of method, i.e. APEKS. The result of the research is a universal methodology, and it consequently may be applied in other surface mines with similar exploitation parameters.
\end{abstract}

\section{Introduction}

The vehicle transport is a dominating type of technological transport in rock mines, its profitability is strictly related to the operating costs. A rational choice of transport system using haul trucks should result from a thorough analysis of technical and economic aspects. Moreover, haul trucks should be chosen taking into account all significant operational parameters and adapted to specific mining-geological conditions as elements of the transport system together with loading machines. Considering the above aspects this paper attempts to prepare universal criteria and methods for assessment and selection of means of haul truck transport in surface rock mines $[1,2]$. Also practical application of multi-criteria optimisation was presented together with APEKS - one of this direction methods. The applied tool allowed to put in order alternative suggestions of solutions (options) existing in the analysed transport system of a given surface mine. The suggested methodology is universal in nature, therefore it can be applied in other mining plants.

\section{Processing system selection}

The complexity of haul trucks selection issues causes that the choice between haul trucks featuring numerous and diversified practical parameters should consider the issue of decision support.

A consistent family of criteria is suggested below, which in as good as possible way characterise the issue of haul trucks selections in a surface rock mine, assuming the planned annual output of around 7 million $\mathrm{Mg}$. In addition, when preparing the criteria the issue of appropriate adaptation of the technological system was considered - loading machines (wheel loaders) together with the haul trucks fleet. The criteria originated as a result of previously performed own analyses and can be used to resolve discrete problems of multi-criteria decision making - such as ranking, using a number of optimisation tools.

\subsection{Economic criteria}

K1. Capital expenditure on the technological system (price) - this is a minimised criterion determining the potential procurement price of haul trucks fleet of the analysed type series together with loading machines - wheel loaders of haul trucks. This criterion is expressed in $[€]$.

K2. Unit operating costs of the processing system - this is a minimised criterion aggregating all significant components of operating costs of the technological system (fleet of haul trucks and loaders) allocated to individual haul trucks type series. It comprises main components of operating costs, including such as costs of fuel, tyres, operational fluids, technical inspections and services (including the cost of authorised service, and also of own work) as well as of spare parts. The operating cost components comprise also: expenditure on roads maintenance, operators and supervisors payroll; insurance of and taxes on means of transport, depreciation and other administrative charges. This criterion aggregates all

\footnotetext{
* Corresponding author: mpatyk@agh.edu.pl
} 
operating costs referred to the performed transport work $[1,2]$. This criterion was expressed in $[€ / \mathrm{Mg}]$.

\subsection{Technological criteria}

K3. Transport capacity - this is a maximised criterion defining the technological capacity of haul trucks type series understood as the transport work referred to the unit amount of output transported during one hour. This criterion was expressed in $[\mathrm{Mg} / \mathrm{h}]$.

K4. The size of machinery fleet is a minimised criterion defining the minimum number of haul trucks and loading machines necessary to ensure the planned capacity of the mine technological transport [pcs.].

K5. Loading time - is a minimised criterion defining an averaged time of loading by a wheel bucket loader for individual type series of haul trucks to the rated capacity of the open platform. This criterion was expressed in [sec].

K6. Transport cycle time is a minimised criterion defining an average time of travel with the load and the time of return travel estimated on the basis of a detailed speed profile referred to the longitudinal profile of the transport route from the extraction face to the preparation plant (Fig. 1). To this end the travel times were analysed, taking into account flat, uphill and downhill sections. The criterion was expressed in [sec].

K8. Haul trucks usage index - determined as a percentage share of the working time recorded by the telemetric system, taking into account disturbances to all its components, including the Idle Work Time (IWT) and the Time of Waiting for Work (TWW). Because of the specific nature of technology, factors delaying the cycle realisation time were additionally considered - Capacity Losses (CL). The measure obtained in this way is named Total Effective Equipment Performance (TEEP) - Operating time (OT). The operating time was taken as the total usage time less the planned downtimes related to the planned machines maintenance and other breaks (like the shift transition etc.). This criterion was expressed in $[\%]$.

\subsection{Utilization criteria}

K7. State of reserve is a minimised criterion defining the necessary number of haul trucks remaining as a cold reserve, necessary to maintain an appropriate transport capacity of the system. This figure depends also on the size of transport machinery fleet and on the planned average technical readiness [3]. This criterion is expressed in [pcs.].

K9. Turning radius is a minimised criterion defining the catalogue value of the minimum turn back radius of a haul truck. The value of this criterion is expressed in $[\mathrm{m}]$.

K10. Unit fuel consumption - is a minimised criterion describing the volume of the used diesel oil referred to the transported weight of the output by the analysed type series of haul trucks. The value of this criterion is expressed in [1/Mg].

K11. Number of drivers is a minimised criterion defining the necessary number of drivers depending on the size of machinery fleet, assuming the impact of driver's psychophysical state on the Driver Vehicle - Environment system (D-V-E), i.e. the smaller number of drivers the smaller risk of unfavourable random event occurrence (accident, queue for loading, etc.,) [4]. The value of this criterion is expressed in [pcs.].

K12. The number of loader dumping cases is a minimised criterion defining the relationship of loader bucket's capacity and load capacity to the capacity and load capacity of the haul truck open platform enabling obtaining the rated capacity. The criterion is expressed in [pcs.].

The following analysis was carried out as an example, with a possibility to modify the adopted criteria and also to introduce new ones; e.g. the criterion of frequent replacement or repair of open platforms for highly abrasive minerals. Three type series of haul trucks were taken as decision options, with the rated load capacity of: 40, 60, and $90 \mathrm{Mg}$. The adopted decision options were analysed taking into account loading machines, consisting of a fleet of wheel bucket loaders, with a bucket of $8 \mathrm{~m}^{3}$ capacity.

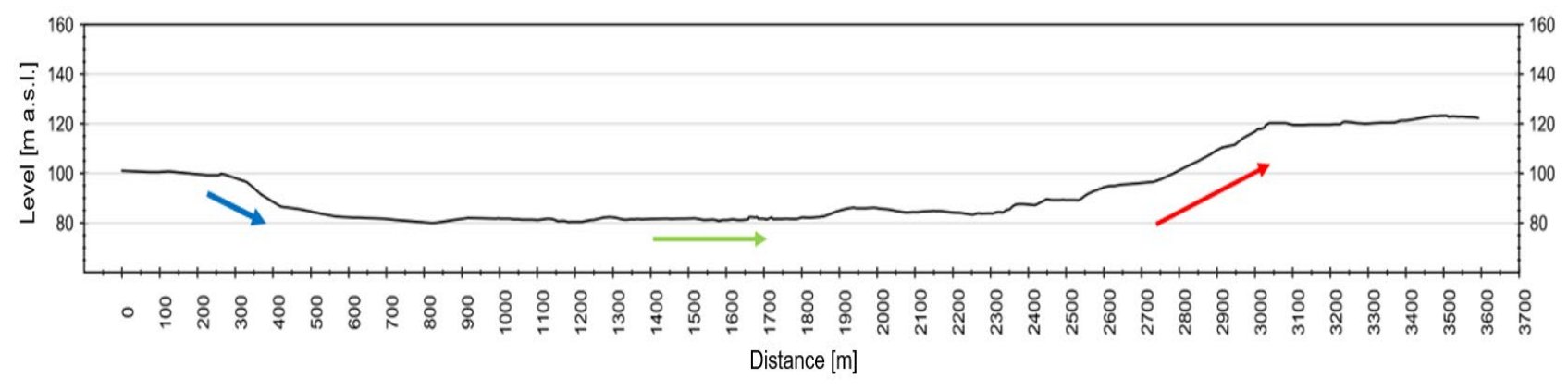

Fig. 1. Longitudinal profile of the transport route. 


\section{Determination of criteria weightings by decision makers}

The APEKS method was used to resolve the issue of decisions ranking [5]. The essence of the method is based on a logical flow chart (algorithm), consisting of 10 action steps. As the final effect it is possible to take a supported decision on the selection of considered options in terms of taken into account criteria, treating the input data as certain. The assessment by the APEKS method consists in the introduction of an idealised fictitious option $W_{A}$ being a benchmark for the actual options being compared (Tab. 1).

At the performance of multi-criteria choice it is necessary to specify (Tab. 1) all possible options (haul trucks) $W_{1}, W_{2}, \ldots W_{n}$ and all criteria, both quantitative and qualitative $K_{1}, K_{2}, \ldots K_{n}$.

Quantitative criteria are expressed here in direct units defining e.g. costs or time. The values of quantitative criteria were determined using the technical and economic data and the results of carried out studies.

The weights $\left(w_{j}\right)$ of all real options assessments were determined applying the forced decisions method in accordance with [5]. The forced decisions method consists in specifying all criteria and making comparisons between each of them, choosing each time this criterion, from the two being compared, which is more significant. Having summed up values of each criterion obtained in this comparison the value of its weight $\left(w_{j}\right)$ is determined in accordance with relationship:

$$
w_{j}=\frac{d_{j}}{N}
$$

where:

$d_{j}$ - value of summed up values obtained for the $j$-th criterion compared with the forced decisions method, $N$ - number of possible forced decisions, determined by the following relationship:

$$
N=\frac{n \cdot(n-1)}{2}
$$

For all adopted criteria the weights are estimated by the forced decisions method, comparing each criterion acc. to the determined procedure, preparing an appropriate table [6]. Weights of individual criteria were averaged based on the decision of a group of scientific staff specializing in the issues of surface mining and of machinery use in mining as well as of a group of mining managers managing large surface mines in Poland (Tab. $2 \mathrm{a}$ and $2 \mathrm{~b}$ ).

According to the first group of decision makers the most important criteria are: the unit operating cost expressed in $[€ / \mathrm{Mg}]\left(W_{i j}=0.167\right)$, the unit fuel consumption $[1 / \mathrm{Mg}]\left(W_{i j}=0.152\right)$, and the haul truck usage index [\%] $\left(W_{i j}=0.138\right)$. In the case of the second group of decision makers, the highest weight criterion is - as above - the unit operating cost $\left(W_{i j}=0.167\right)$, the next most important criteria include: the number of drivers expressed in [pcs.] $\left(W_{i j}=0.152\right)$ and the unit fuel consumption in $[1 / \mathrm{Mg}]\left(W_{i j}=0.121\right)$.

Table 1. Input values of criteria for the analysed options (haul trucks).

\begin{tabular}{|l|l|c|c|c|c|c|c|}
\hline \multicolumn{2}{|c|}{ Criterion } & unit & W40 & W60 & W90 & W $_{\mathbf{A}}$ & $\mathbf{W}_{\mathbf{i}}$ \\
\hline K1 & Capital expenditure (price) & $\mathrm{k} €$ & 8250 & 9000 & 9375 & 8250 & $\mathbf{0 . 0 4}$ \\
\hline K2 & Unit operating costs & $€ / \mathrm{Mg}$ & 0.62 & 0.60 & 0.52 & 0.52 & $\mathbf{0 . 1 7}$ \\
\hline K3 & Transport capacity & $\mathrm{Mg} / \mathrm{h}$ & 171.4 & 240.0 & 321.4 & 321.4 & $\mathbf{0 . 1 1}$ \\
\hline K4 & Size of machinery fleet & pcs. & 15 & 12 & 9 & 9 & $\mathbf{0 . 1 1}$ \\
\hline K5 & Haul truck loading time & sec. & 117 & 156 & 234 & 117 & $\mathbf{0 . 0 8}$ \\
\hline K6 & Transport cycle time & sec. & 599 & 619 & 659 & 599 & $\mathbf{0 . 0 7}$ \\
\hline K7 & State of cold reserve & pcs. & 2 & 2 & 1 & 1 & $\mathbf{0 . 0 4}$ \\
\hline K8 & Haul trucks usage index & \% & 97.2 & 92.9 & 89.1 & 97.2 & $\mathbf{0 . 1 2}$ \\
\hline K9 & Turning radius & m & 7.2 & 8.5 & 10.1 & 7.2 & $\mathbf{0 . 0 1}$ \\
\hline K10 & Unit fuel consumption & {$[1 / \mathrm{Mg}$ transported] } & 0.150 & 0.146 & 0.152 & 0.146 & $\mathbf{0 . 1 4}$ \\
\hline K11 & Number of drivers & pcs. & 30 & 24 & 18 & 22 & $\mathbf{0 . 0 8}$ \\
\hline K12 & Number of loader buckets & pcs. & 3 & 4 & 6 & 3 & $\mathbf{0 . 0 5}$ \\
\hline
\end{tabular}


Table 2a. Decision matrices for the analysed haul trucks optimised by means of Apeks method, assessed by decision makers: scientific staff.

\begin{tabular}{|c|c|c|c|c|c|c|c|c|c|c|c|c|c|c|}
\hline & K1 & K2 & K3 & K4 & K5 & K6 & K7 & K8 & K9 & K10 & K11 & K12 & d & Wi \\
\hline K1 & - & 0 & 0 & 0 & 0 & 0 & 1 & 0 & 1 & 0 & 0 & 0 & 2 & $\mathbf{0 . 0 3 0}$ \\
\hline K2 & 1 & - & 1 & 1 & 1 & 1 & 1 & 1 & 1 & 1 & 1 & 1 & 11 & $\mathbf{0 . 1 6 7}$ \\
\hline K3 & 1 & 0 & - & 1 & 1 & 1 & 1 & 0 & 1 & 0 & 1 & 1 & 8 & $\mathbf{0 . 1 2 1}$ \\
\hline K4 & 1 & 0 & 0 & - & 1 & 1 & 1 & 0 & 1 & 0 & 1 & 1 & 7 & $\mathbf{0 . 1 0 6}$ \\
\hline K5 & 1 & 0 & 0 & 0 & - & 1 & 1 & 0 & 1 & 0 & 1 & 1 & 6 & $\mathbf{0 . 0 9 1}$ \\
\hline K6 & 1 & 0 & 0 & 0 & 0 & - & 1 & 0 & 1 & 0 & 1 & 1 & 5 & $\mathbf{0 . 0 7 6}$ \\
\hline K7 & 0 & 0 & 0 & 0 & 0 & 0 & - & 0 & 1 & 0 & 1 & 1 & 3 & $\mathbf{0 . 0 4 5}$ \\
\hline K8 & 1 & 0 & 1 & 1 & 1 & 1 & 1 & - & 1 & 0 & 1 & 1 & 9 & $\mathbf{0 . 1 3 6}$ \\
\hline K9 & 0 & 0 & 0 & 0 & 0 & 0 & 0 & 0 & - & 0 & 1 & 0 & 1 & $\mathbf{0 . 0 1 5}$ \\
\hline K10 & 1 & 0 & 1 & 1 & 1 & 1 & 1 & 1 & 1 & - & 1 & 1 & 10 & $\mathbf{0 . 1 5 2}$ \\
\hline K11 & 1 & 0 & 0 & 0 & 0 & 0 & 0 & 0 & 0 & 0 & - & 0 & 1 & $\mathbf{0 . 0 1 5}$ \\
\hline K12 & 1 & 0 & 0 & 0 & 0 & 0 & 0 & 0 & 1 & 0 & 1 & - & 3 & $\mathbf{0 . 0 4 5}$ \\
\hline
\end{tabular}

Table 2b. Decision matrices for the analysed haul trucks optimised by means of Apeks method, assessed by decision makers: mine managers.

\begin{tabular}{|c|c|c|c|c|c|c|c|c|c|c|c|c|c|c|}
\hline & K1 & K2 & K3 & K4 & K5 & K6 & K7 & K8 & K9 & K10 & K11 & K12 & d & Wi \\
\hline K1 & - & 0 & 0 & 0 & 0 & 0 & 1 & 0 & 1 & 0 & 0 & 1 & 3 & $\mathbf{0 . 0 4 5}$ \\
\hline K2 & 1 & - & 1 & 1 & 1 & 1 & 1 & 1 & 1 & 1 & 1 & 1 & 11 & $\mathbf{0 . 1 6 7}$ \\
\hline K3 & 1 & 0 & - & 1 & 1 & 1 & 1 & 0 & 1 & 0 & 0 & 1 & 7 & $\mathbf{0 . 1 0 6}$ \\
\hline K4 & 1 & 0 & 0 & - & 1 & 1 & 1 & 1 & 1 & 0 & 0 & 1 & 7 & $\mathbf{0 . 1 0 6}$ \\
\hline K5 & 1 & 0 & 0 & 0 & - & 0 & 1 & 0 & 1 & 0 & 0 & 1 & 4 & $\mathbf{0 . 0 6 1}$ \\
\hline K6 & 1 & 0 & 0 & 0 & 1 & - & 0 & 0 & 1 & 0 & 0 & 1 & 4 & $\mathbf{0 . 0 6 1}$ \\
\hline K7 & 0 & 0 & 0 & 0 & 0 & 1 & - & 0 & 1 & 0 & 0 & 0 & 2 & $\mathbf{0 . 0 3 0}$ \\
\hline K8 & 1 & 0 & 1 & 0 & 1 & 1 & 1 & - & 1 & 1 & 0 & 0 & 7 & $\mathbf{0 . 1 0 6}$ \\
\hline K9 & 0 & 0 & 0 & 0 & 0 & 0 & 0 & 0 & - & 0 & 0 & 0 & 0 & $\mathbf{0 . 0 0 0}$ \\
\hline K10 & 1 & 0 & 1 & 1 & 1 & 1 & 1 & 0 & 1 & - & 0 & 1 & 8 & $\mathbf{0 . 1 2 1}$ \\
\hline K11 & 1 & 0 & 1 & 1 & 1 & 1 & 1 & 1 & 1 & 1 & - & 1 & 10 & $\mathbf{0 . 1 5 2}$ \\
\hline K12 & 0 & 0 & 0 & 0 & 0 & 0 & 1 & 1 & 1 & 0 & 0 & - & 3 & $\mathbf{0 . 0 4 5}$ \\
\hline
\end{tabular}

\section{The method of ranking APEKS permissions}

The next step in the procedure consists in calculating percentage estimations for considered mixed criteria (quantitative and qualitative) taking into account possible options, acc. to relationship (3) for percentage critical values [5]:

$$
c_{i j}=\left[\left(\frac{a_{i j}}{a_{A j}}\right)^{ \pm 1} \cdot 100\right]^{w_{j}}
$$

where:

$a_{i j}$ - estimated value of the i-th option in the light of the $j$ th criterion,

$a_{A j}$ - estimated value of the Apeks option in the light of the $j$-th criterion,

$w_{j}$ - weight of the $j$-th criterion.

Sign \pm at the exponent depends on the optimisation acc. to the specific criterion importance, consisting in minimisation (-) or maximisation $(+)$. The above procedure is presented in Tab. 2 .

The total value of estimates for each analysed option (haul truck) is calculated from the relationship [5]:

$$
K_{r i}=\prod_{j=1}^{j=n}\left[\left(\frac{a_{i j}}{a_{A j}}\right)^{ \pm 1} \cdot 100\right]^{w j}
$$

Then by means of an isomorphic transformation the optimised option Max $K_{r i}$ is selected, marked red in the table 3.

The technological system with haul trucks of $90 \mathrm{Mg}$ capacity $\left(K_{r i}=89.2 \%\right)$ is the most favourable option in the presented analysis. This system features the lowest unit operating cost, by $13 \%$ lower than that for haul trucks of $40 \mathrm{Mg}$ capacity and by $4 \%$ for haul trucks of $60 \mathrm{Mg}$ capacity. Moreover, this type series features the highest transport capacity (by 33\% higher than W60, and by $87.5 \%$ higher than W40) and - what is very significant the lowest size of the machinery fleet, which translates directly into the number of drivers and operators.

A bar chart (Fig. 2) was prepared for each haul truck to present clearly the results of multi-criteria analysis obtained by means of the APEKS method.

The last step consists in the analysis of the optimum option characteristics values using the characteristics of other options in the light of all considered criteria and based on it - showing the weakest and the strongest characteristic with regard to the given criterion.

In the light of adopted criteria a fleet of haul trucks of $90 \mathrm{Mg}$ capacity is the most favourable selection option. The result of analysis was affected primarily by weights of criteria related to the operating cost of the entire technological system. According to the analyst, this is the universal and important parameter for all expert. 
Table 3. Relative values of estimates $c_{i j}$ and relative percentage critical values $K_{r i}$ for mixed criteria taken into account in the analysis and for the considered options (haul trucks).

\begin{tabular}{|c|l|c|c|c|c|}
\hline \multicolumn{2}{|c|}{ Criterion } & unit & W40 & W60 & W90 \\
\hline K1 & Capital expenditure (price) & $\mathrm{k} €$ & 1.191 & 1.187 & 1.185 \\
\hline K2 & Unit operating costs & $€ / \mathrm{Mg}$ & 2.093 & 2.106 & 2.154 \\
\hline K3 & Transport capacity & $\mathrm{Mg} / \mathrm{h}$ & 1.571 & 1.633 & 1.688 \\
\hline K4 & Size of machinery fleet & pcs. & 1.544 & 1.581 & 1.630 \\
\hline K5 & Haul truck loading time & sec. & 1.417 & 1.387 & 1.345 \\
\hline K6 & Transport cycle time & sec. & 1.369 & 1.366 & 1.360 \\
\hline K7 & State of cold reserve & pcs. & 1.160 & 1.160 & 1.191 \\
\hline K8 & Haul truck usage index & \% & 1.748 & 1.738 & 1.729 \\
\hline K9 & Turning radius & m & 1.036 & 1.034 & 1.033 \\
\hline K10 & Unit fuel consumption & {$[1 / \mathrm{Mg}$ transported] } & 1.867 & 1.874 & 1.863 \\
\hline K11 & Number of drivers & pcs. & 1.407 & 1.433 & 1.468 \\
\hline K12 & Number of loader buckets & pcs. & 1.233 & 1.217 & 1.195 \\
\hline & \multicolumn{1}{|c}{ K $_{\text {ri }}$} & & $\mathbf{7 9 . 6 8}$ & $\mathbf{8 3 . 1 9}$ & $\mathbf{8 9 . 2 0}$ \\
\hline
\end{tabular}

Economic criteria have been intentionally divided into two components - capital expenditure cost and the total operating cost, because of their grate importance for the majority of decision makers. However, they recognized operating cost as criterion with the highest relative importance. It indicated that the main stress is laid on economic criteria.

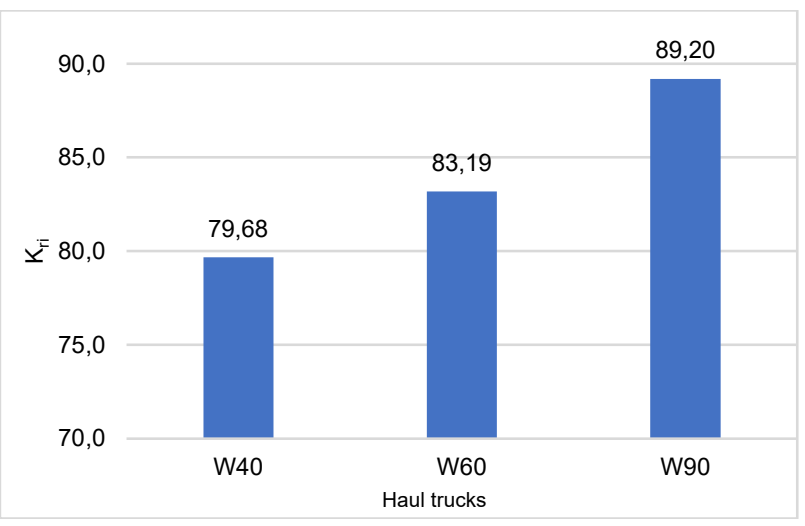

Fig. 2. Relative percentage values of $K_{r i}$ estimates for the analysed haul trucks for the adopted criteria.

The weakest features of the most favourable option (W90) include the capital expenditures, which value is $13.6 \%$ higher than for the W40 option, the haul truck loading time and the biggest number of buckets, resulting from a higher capacity and the same size of loaders for all haul truck options, the transport cycle time, the haul truck usage index, turning radius, and also the highest unit fuel consumption. Moreover the construction features and the haul trucks usage index, proved to be important, with the emphasis fuel consumption.

\section{Summary}

The analysis of haul trucks choice for the planned annual output presented in the paper, especially at the stage of transport designing, enables choosing the most favourable option in the light of adopted criteria.

The results of the analysis, clearly show the most important criteria accented by the experts in the field of mining technology operating cost. Within the next assessment greater emphasis has to be put on economic criteria to better reflect recent resolve this type of problem.

The results of the analyses, show the best solution from the reliability point of view, that mean - less number of trucks with bigger capacity if trucks are very reliable. In in the event of failure of truck the mine can has problems with reaching output plans. Hoverer all the technical object can be repaired, mean that the operation process of particular trucks will always be at least two state: work - repair.

Moreover, the carried out analysis takes into account relations between loading machines and technological transport vehicles. In such issues the most important aspect consists in the formulation of authoritative criteria, classifying in as good as possible way the nature of the issue. Appropriate estimation of weights of the criteria taken for analysis is an equally important aspect. The APEKS method used in the considerations in its nature is only a support for decision making. This method may be used both at the stage of designing and also during subsequent operation of the machinery system. However, the application of the APEKS method at the stage of designing may be related to certain limitations. They result from incomplete information on the value of criteria for individual design assumptions. This method is especially useful for decision support, where there is a large number of criteria, i.e. more than 9. It is worth emphasising that the application of weight assessments for individual criteria as well as total assessments of analysed options in the APEKS method enables indicating so-called weak and strong features of options, which allows their further analysis and a possibility to modify that feature. 
The APEKS method, adapted to the multi-criteria support for haul trucks selection, shows also certain imperfections, in particular on the level of assigning the criteria weights by means of the forced decisions method. Also, a high subjectivity of final rankings should be considered unfavourable, related to a more difficult possibility to verify own preferences of individual experts.

\section{References}

1. P. Bodziony, Z. Kasztelewicz, P. Sawicki, Archives of Mining Sciences, 61, 223-243 (2016)

2. A.A. Bazzazi, M. Osanloo, B. Karimi, Archives of Mining Sciences, 54, 301-320 (2009)

3. J.M. Czaplicki. Shovel-Truck Systems. Modelling analysis and calculation (CRC Press, 2009)

4. W. Silka, Energochłonność ruchu samochodu (WNT, 1997, in Polish)

5. J. Szybka and R. Pilch, Proceedings of XXXIV Winter School of Reliability (2006) 